\title{
Meal patterns and cooking practices in Southern France and Central England
}

\author{
Clare Pettinger ${ }^{1, *} \dagger$, Michelle Holdsworth ${ }^{2}$ and Mariette Gerber ${ }^{3}$ \\ 'School of Biosciences, University of Nottingham, Nottingham, UK: ${ }^{2}$ UR 106, Nutrition, Food \& Society, \\ Institut de Recherche pour le Développement, WHO Nutrition Collaborating Centre, Montpellier, France: \\ ${ }^{3}$ Centre de Recherche en Cancérologie, INSERM-CRLC, Montpellier, France
}

Submitted 1 June 2005: Accepted 10 January 2006

\begin{abstract}
Objective: To evaluate whether meal patterns and cooking practices in Central England and Mediterranean France conform to popular stereotypes, eating together as a household, preparation of meals, food purchasing patterns, cooking practices and eating out were investigated.

Design: Cross-sectional studies conducted simultaneously in April 2001 using selfadministered postal questionnaires.

Setting: England (Nottingham, East Midlands) and France (Montpellier, LanguedocRoussillon).

Subjects: A stratified random sample of 1000 males and 1000 females aged 18-65 years was generated from the electoral roll in each country. The final sample comprised 826 subjects in England (58\% males, $42 \%$ females; mean age 44 years) and 766 subjects in France (42\% males, 58\% females; mean age 42 years). Analyses were conducted on samples standardised for sociodemographic differences.

Results: The French cooked from raw ingredients most often $(P<0.001)$, ate together as a household more regularly $(P<0.001)$ and were most likely to follow a regular meal pattern of three meals a day. On the other hand, the English relied more on ready-prepared $(P<0.001)$ and take-away $(P<0.001)$ meals, as well as on energy-dense snack foods such as crisps $(P<0.001)$. Females in both countries reported having most responsibility for preparing meals.

Conclusions: Some of the study's findings confirm popular stereotypes of French and English food cultures, as the importance of the convivial aspects of eating, as well as more traditional practices such as cooking meals from basic ingredients, structured mealtimes and less between-meal snacking, remain more prominent within the French population. This may contribute to the differences in prevalence of obesity seen between the two countries.
\end{abstract}

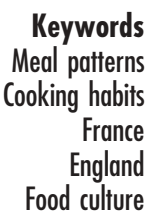

England and France are neighbouring countries sharing similarities in their history and cultural heritage, but great differences in the development of distinctive culinary cultures. Their cuisines are popularly seen as offering striking contrasts, even though they have been in mutual contact and influenced each other for many centuries ${ }^{1}$. This contact has been described historically as creating many tensions between the two nations in terms of their national identities ${ }^{2}$.

Food choice in humans is a complex process and its many determinants have been well documented over the last 60 years $^{3,4}$. Food choice patterns differ throughout Europe and socio-cultural determinants are known to

†Present address: Faculty of Health and Social Work, University of Plymouth, Peninsula Allied Health Centre, Derriford Road, Plymouth PL6 9BH, UK. influence these patterns ${ }^{5,6}$. Culture has a major role in determining where and how foods are consumed ${ }^{7,8}$ and food is a way of expressing sociability and hospitality ${ }^{9}$, as mealtimes bring groups together, both physically and symbolically ${ }^{10,11}$.

Traditionally, women are more likely to be responsible for the greater share of food-related activities ${ }^{9}$ but there is a suggestion of change in this traditional housekeeping role as women are increasingly going out to work, leading to a 'de-skilling' of certain food preparation tasks, an increasing influence of convenience on food choice in the $\mathrm{UK}^{12}$ and a movement towards simpler meals and recipes in France ${ }^{13}$.

Food is a major source of pleasure for almost all humans ${ }^{14}$ and is known to play an essential role in France and Southern Europe in strengthening social ties ${ }^{15}$. The kitchen in France has been described as a convivial room 
where everyone meets ${ }^{15}$. In England, on the other hand, food may be regarded as a necessity by many, and this has been well documented since the early $1800 \mathrm{~s}^{16,17}$.

Another important influence on food choice is the increasing availability of places to eat out. People eat away from the home either out of necessity or purely for pleasure $^{18}$. This is of particular relevance in England, where the population consumes more convenience food than any other European country ${ }^{19}$, and may be a factor in the nation's increasing prevalence of obesity. In France, on the other hand, food tends to 'follow the flag' and national traditions have held their own more than in England ${ }^{1}$. This tradition seems to be shifting, however, with a rise in the popularity of American-style fast-food outlets in France. This is particularly the case for younger adults in Southern France, who have been shown to be moving away from the consumption of foods characteristic of a traditional Mediterranean diet ${ }^{20}$.

The present investigation evolved from a previous study $^{21}$ confirming that a population in a Mediterranean French region consumed a healthier diet than a Central England population; the contrasts shown in food consumption patterns between these two areas highlighted the need to investigate the reasons for these differences. Substantial differences in the attitudes to and beliefs about food and health have also been observed between these two populations ${ }^{22}$, with the French valuing the pleasurable and social aspects of eating whereas convenience, i.e. freedom from effort or difficulty, was an important factor influencing English respondents' food choices. Some aspects of the underlying food culture in these two nations are explored in the current paper, in particular eating together as a household, preparation of meals, food purchasing patterns, cooking practices and eating-out patterns.

\section{Methods}

\section{Participants and recruitment}

Self-administered postal questionnaires were distributed in April 2001 to 1000 males and 1000 females aged 18-65 years in Montpellier, France and Nottingham, England. Both stratified random samples were generated from the electoral register. The final samples comprised 826 subjects in England and 766 subjects in France, providing final adjusted response rates of $42.8 \%$ and $52.4 \%$, respectively.

The following were considered to be important for optimising response rates $^{23,24}$ : the questionnaire was kept as short as possible; the covering letter was written on headed notepaper, had an informal tone and was handsigned; a stamped addressed envelope (SAE) was enclosed and a stamp used rather than industrial franking; the questionnaires were distributed during springtime and were posted to arrive just before the weekend; reminder letters were posted to those individuals who had not already responded one month after the initial mailing, with a further copy of the questionnaire and SAE; during the period of questionnaire distribution, the study was publicised by conducting interviews with local radio, television and newspapers, appealing to individuals to complete the questionnaire.

\section{Questionnaire validity and reliability}

The questionnaire items were deemed to have face and content validity by nine experts within the disciplines of psychology, anthropology, epidemiology and public health nutrition. Face-to-face meetings with these professionals were conducted, generating discussions on each of the proposed concepts and ideas for question inclusion. As a result, the construction of questions evolved, and wording and structure were modified and developed. Additionally, the questionnaire was piloted in each country in a population similar to the main sample to ensure that questions were properly understood. The questionnaire was initially translated into French by a bilingual speaker; subsequently both English and French versions were verified for language and cultural acceptance, the latter by 15 native French speakers.

\section{Data processing and analysis}

The data from the questionnaires were coded and inputted into SPSS. In order to reduce error rate, a 10\% random sample of the questionnaires was verified to determine an error rate of $<1 \%^{25}$. The actual error rate was $0.05 \%$ (English data) and $0.02 \%$ (French data) of keystrokes, so double data entry was deemed unnecessary. All data were analysed using SPSS $^{26}$.

Variables were grouped according to the research question and cross-tabulations were carried out incorporating the chi-square test for independence. Frequency variables, for example, were regrouped so that analyses were carried out on three categories: 'daily', 'at least once a week' (grouped from 2-6 times per week and at least once a week) and 'at least once a month or never' (grouped from at least once a month, less often than once a month and never). Following this, nominal regression was carried out which adjusted the samples ensuring that any difference seen was not due to confounding variables such as age group, gender, body mass index (BMI), educational level or employment status.

\section{Results}

\section{Sociodemographic profile}

The sample generated a gender spread that was different from the populations from which they were drawn ${ }^{27,28}$. A larger proportion of the French sample was aged $<35$ years (Table 1), which may partly explain why there were more French than English respondents in full-time higher education. In terms of BMI, there were significantly more overweight/obese subjects in the English than in the 
Table 1 Sociodemographic characteristics of English $(n=826)$ and French $(n=766)$ samples

\begin{tabular}{|c|c|c|c|c|c|}
\hline & \multicolumn{2}{|c|}{$\begin{array}{l}\text { Nottingham, } \\
\text { England }\end{array}$} & \multicolumn{2}{|c|}{$\begin{array}{l}\text { Montpellier, } \\
\text { France }\end{array}$} & \multirow[b]{2}{*}{$X^{2}(\mathrm{df})$} \\
\hline & $n$ & $\%$ & $n$ & $\%$ & \\
\hline Gender & & & & & $39.9(1)^{\star *}$ \\
\hline Males & 478 & 58.2 & 322 & 42.3 & \\
\hline Females & 344 & 41.8 & 440 & 57.7 & \\
\hline Age group & & & & & $24.0(2)^{\star *}$ \\
\hline $18-35$ years & 227 & 28.0 & 274 & 36.2 & \\
\hline $36-50$ years & 339 & 41.8 & 229 & 30.3 & \\
\hline $51-65$ years & 245 & 30.2 & 254 & 33.6 & \\
\hline Mean age & 43.5 & & 42.1 & & \\
\hline $\begin{array}{l}\text { Body mass index } \\
\left(\mathrm{kg} \mathrm{m}^{-2}\right)\end{array}$ & & & & & $101.5(3)^{\star \star}$ \\
\hline$<18.5$ & 24 & 3.0 & 68 & 9.0 & \\
\hline $18.5-24.9$ & 390 & 49.3 & 500 & 66.4 & \\
\hline $25-29.9$ & 279 & 35.3 & 146 & 19.4 & \\
\hline$\geq 30.0$ & 98 & 12.4 & 39 & 5.2 & \\
\hline Highest qualification & & & & & $192.2(4)^{\star *}$ \\
\hline $\begin{array}{l}\text { Higher education } \\
\text { ( } \geq 3 \text { years) }\end{array}$ & 214 & 26.4 & 304 & 40.2 & \\
\hline Employment status & & & & & $63.8(5)^{\star *}$ \\
\hline Paid employment & 574 & 69.8 & 417 & 54.9 & \\
\hline Higher education & 22 & 2.7 & 88 & 11.6 & \\
\hline Unemployed & 35 & 4.3 & 40 & 5.3 & \\
\hline Retired & 86 & 10.5 & 99 & 13.0 & \\
\hline Vegetarian & 56 & 6.8 & 20 & 2.6 & $15.1(1)^{\star *}$ \\
\hline
\end{tabular}

${ }^{*}, P<0.05 ;{ }^{* *}, P<0.001$

French sample. More French than English respondents were better educated and more English than French respondents described themselves as vegetarian.

\section{Eating together as a bousebold}

Nearly two-thirds of French (64.8\%), compared with just over half of English respondents (51.0\%), reported eating together as a household on a daily basis $\left(\chi^{2}=43.6\right.$; $\mathrm{df}=2 ; P<0.001$ ) (Fig. 1). However, younger adults were less likely to eat together in both countries (Table 2).

\section{Food purchasing patterns}

More females in both countries were responsible for food purchase but, in particular, more female respondents in

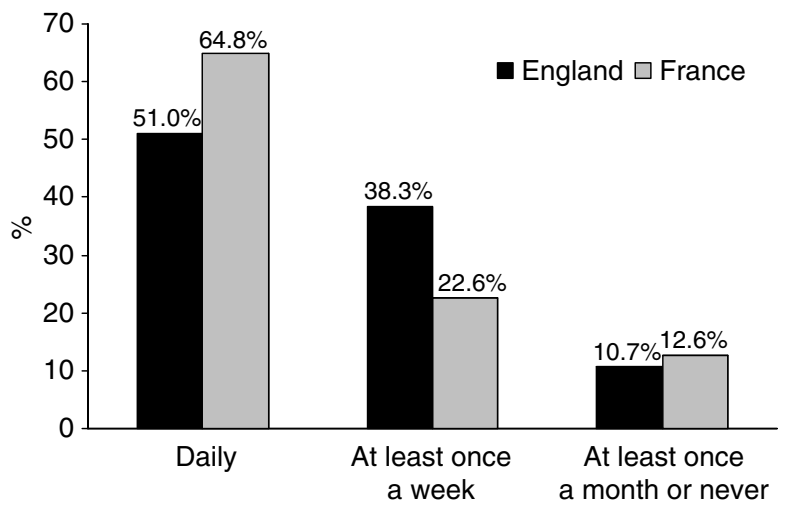

Fig. 1 Frequency of eating together as a household in English and French samples
Table 2 Age trends for components of meal patterns and cooking habits

\begin{tabular}{|c|c|c|c|c|}
\hline \multirow[b]{2}{*}{ Age group } & \multicolumn{2}{|c|}{$\begin{array}{l}\text { England } \\
(n=726)\end{array}$} & \multicolumn{2}{|c|}{$\begin{array}{c}\text { France } \\
(n=739)\end{array}$} \\
\hline & $\%$ & $\chi_{\mathrm{df}=2}^{2}$ & $\%$ & Adjusted $\dagger \chi_{\mathrm{df}=2}^{2}$ \\
\hline \multicolumn{5}{|c|}{ Eating together as a household daily } \\
\hline $18-35$ years & 47.3 & $16.9^{\star *}$ & 58.6 & $8.5^{\star}$ \\
\hline $36-50$ years & 45.6 & & 65.9 & \\
\hline $51-65$ years & 62.8 & & 70.8 & \\
\hline \multicolumn{5}{|c|}{ Eating breakfast daily } \\
\hline $18-35$ years & 63.4 & $20.1^{\star \star}$ & 77.4 & $19.3^{\star \star}$ \\
\hline $36-50$ years & 69.3 & & 88.6 & \\
\hline $51-65$ years & 81.6 & & 89.8 & \\
\hline \multicolumn{5}{|c|}{ Cooking from raw ingredients daily } \\
\hline $18-35$ years & 12.5 & $33.9^{\star *}$ & 50.5 & $29.1^{\star \star}$ \\
\hline $36-50$ years & 19.5 & & 62.4 & \\
\hline $51-65$ years & 34.3 & & 73.6 & \\
\hline \multicolumn{5}{|c|}{ Using ready-prepared meals $\ddagger$ at least once a week } \\
\hline $18-35$ years & 27.4 & $11.7^{*}$ & 19.0 & 4.6 \\
\hline $36-50$ years & 18.3 & & 17.3 & \\
\hline $51-65$ years & 15.0 & & 12.1 & \\
\hline
\end{tabular}

${ }^{*} P<0.05 ;{ }^{* *} P<0.001$.

† Adjusted for gender, education level and body mass index group.

$\ddagger$ 'Ready-prepared meals' defined as meals requiring re-heating, i.e. equivalent to 'oven-ready'.

England (72.4\%) than in France (58.4\%) reported deciding which foods to purchase. Similarly, more females in England (73.0\%) than France (55.0\%) reported doing the food shopping (Table 3).

\section{Cooking babits and food preparation}

Almost two-thirds of French respondents (61.9\%) reported cooking a meal from raw ingredients daily, compared with less than a quarter of English respondents (22.2\%) (Table 4). Three-quarters of French females (74.0\%) compared with less than half (44.8\%) of French males reported cooking a meal from raw ingredients on a daily basis $\left(\chi^{2}=66.2 ; \mathrm{df}=1 ; P<0.001\right)$. On the other hand, there was no difference between English males (22.8\%) and females (21.4\%). When considering age, the pattern was similar for both countries. The overall trend showed that older age groups were more likely to cook from raw ingredients (Table 2).

The finding that less English respondents cooked from raw ingredients was reflected in the fact that more English (53.6\%) than French (46.5\%) respondents reported using ready-prepared (i.e. oven-ready) meals at least once a week. In the English sample, younger adults used readyprepared meals most often (Table 2), but in the French sample this trend was not apparent.

\section{Eating out}

More than three times as many English respondents (23.9\%) than French (7.0\%) reported purchasing a takeaway meal at least once a week. However, there was no difference between the two countries in how often respondents went out for a sit-down meal (Table 4). There was no gender difference in the English sample, but in the 
Table 3 Responsibility for food purchase by gender of English and French respondents

\begin{tabular}{|c|c|c|c|c|c|}
\hline & \multirow{2}{*}{\multicolumn{2}{|c|}{$\begin{array}{c}\text { England } \\
\text { Yes }\end{array}$}} & \multirow{2}{*}{\multicolumn{2}{|c|}{$\begin{array}{c}\text { France } \\
\text { Yes }\end{array}$}} & \multirow[b]{3}{*}{ Adjusted $\dagger \chi_{\mathrm{df}=}^{2}$} \\
\hline & & & & & \\
\hline & $n$ & $\%$ & $n$ & $\%$ & \\
\hline \multicolumn{6}{|c|}{ Deciding which foods are purchased } \\
\hline Males & 141 & 29.6 & 69 & 21.4 & $6.5^{*}$ \\
\hline Females & 249 & 72.4 & 257 & 58.4 & $16.5^{\star \star}$ \\
\hline \multicolumn{6}{|c|}{ Doing the food shopping } \\
\hline Males & 154 & 32.3 & 87 & 27.0 & 2.5 \\
\hline Females & 251 & 73.0 & 242 & 55.0 & $26.7^{\star \star}$ \\
\hline
\end{tabular}

${ }^{*} P<0.05 ;{ }^{* *} P<0.001$

† Adjusted for age, education level and body mass index group.

French sample males (12.2\%) were more than twice as likely as females (4.7\%) to report going out for a sit-down meal at least once a week $\left(\chi^{2}=16.6\right.$; $\left.\mathrm{df}=1 ; P<0.05\right)$.

\section{Mealtime structure}

The majority of respondents in both France and England reported eating breakfast, lunch and an evening meal most days. However, differences were observed between countries for the frequency of eating breakfast and lunch, as more French (84.9\%) than English (71.3\%) respondents reported eating breakfast on a daily basis $\left(\chi^{2}=42.5 ; \mathrm{df}=2 ; P<0.001\right)$. Similarly, more French (91.3\%) than English (77.5\%) respondents reported eating lunch daily $\left(\chi^{2}=56.6\right.$; $\left.\mathrm{df}=2 ; P<0.001\right)$. Over $90 \%$ of French and English respondents reported eating their evening meal every day. Younger adults in both countries were more likely to skip breakfast (Table 2).

\section{Snacking babits}

Differences were seen between the countries for snack food consumption (Table 5), as over half (58.8\%) of English respondents reported eating crisps/fried snacks at least once a week compared with only $6.0 \%$ of French respondents. More English (15.0\%) than French (10.5\%) respondents also reported eating peanuts/nuts at least once a week. There were no differences between countries for the consumption of confectionery. Almost two-thirds of English respondents (63.9\%) reported eating cakes and biscuits at least once a week compared with just over half of the French (55.1\%). Fruit was consumed as a snack on a daily basis by about half of the respondents in each country (Table 5).

\section{Discussion}

This investigation has examined patterns of food behaviour in both countries: cooking and food preparation, mealtimes and snacking habits. The findings confirm popular stereotypes of French and English food cultures, as the importance of the convivial aspects of eating, as well as more traditional practices such as cooking meals from basic
Table 4 Frequency of cooking-related activities, eating out and purchase of ready-prepared meals of English and French respondents

\begin{tabular}{|c|c|c|c|}
\hline Frequency & $\begin{array}{c}\begin{array}{c}\text { England } \\
(n=803)\end{array} \\
\%\end{array}$ & $\frac{\begin{array}{c}\text { France } \\
(n=754)\end{array}}{\%}$ & $\begin{array}{c}\text { Adjusted } \dagger \\
\chi_{\mathrm{df}=2}^{2}\end{array}$ \\
\hline \multicolumn{4}{|c|}{ Cooking a meal from raw ingredients } \\
\hline Daily & 22.2 & 61.9 & $237.9^{* *}$ \\
\hline At least once a week & 64.8 & & \\
\hline At least once a month or never & & & \\
\hline \multicolumn{4}{|l|}{ Using ready-prepared meals $\ddagger, \S$} \\
\hline Daily & 2.1 & 1.4 & $9.9^{* *}$ \\
\hline At least once a week & 51.5 & 45.1 & \\
\hline At least once a month or never & 46.4 & 53.5 & \\
\hline \multicolumn{4}{|c|}{ Going out for a sit-down meal (excluding workplace)‡ } \\
\hline Daily & 0.6 & 0.9 & 12.6 \\
\hline At least once a week & 16.0 & 21.7 & \\
\hline At least once a month or never & 83.4 & 77.3 & \\
\hline \multicolumn{4}{|l|}{ Purchasing a take-away mealf. } \\
\hline At least once a week & 23.9 & 7.0 & $75.1^{\star *}$ \\
\hline At least once a month or never & 76.1 & 92.9 & \\
\hline \multicolumn{4}{|c|}{ 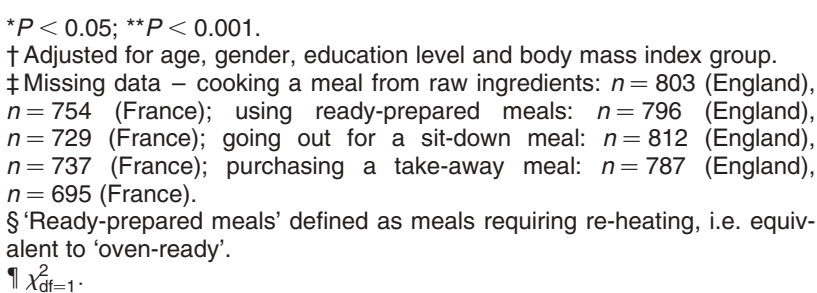 } \\
\hline
\end{tabular}

ingredients and structured mealtimes, remain more prominent within the French population. On the other hand, the English cooked less from raw ingredients, relying more on ready-prepared (oven-ready) and take-away

Table 5 Snack food consumption patterns in English and French samples

\begin{tabular}{|c|c|c|c|}
\hline & $\begin{array}{l}\text { England } \\
(n=803)\end{array}$ & $\begin{array}{c}\text { France } \\
(n=754)\end{array}$ & \\
\hline & $\%$ & $\%$ & $\chi_{\mathrm{df}=2}^{2}$ \\
\hline \multicolumn{4}{|l|}{ Crisps/fried snacks } \\
\hline Daily & 9.3 & 0.3 & $497.0^{\star \star}$ \\
\hline At least once a week & 49.5 & 5.7 & \\
\hline \multirow{2}{*}{\multicolumn{4}{|c|}{ Peanuts/nuts }} \\
\hline & & & \\
\hline Daily & 1.4 & 0.3 & $13.9^{*}$ \\
\hline At least once a week & 13.6 & 10.2 & \\
\hline At least once a month or never & 85.0 & 89.5 & \\
\hline \multicolumn{4}{|l|}{ Confectionery } \\
\hline Daily & 9.4 & 10.2 & 1.4 \\
\hline At least once a week & 51.0 & 47.9 & \\
\hline At least once a month or never & 39.6 & 41.9 & \\
\hline \multicolumn{4}{|l|}{ Biscuits/cakes } \\
\hline Daily & 8.5 & 5.0 & $13.6^{*}$ \\
\hline At least once a week & 55.4 & 50.1 & \\
\hline At least once a month or never & 36.1 & 44.9 & \\
\hline \multicolumn{4}{|l|}{ Fruit } \\
\hline Daily & 49.9 & 49.1 & 0.9 \\
\hline At least once a week & 41.3 & 43.8 & \\
\hline At least once a month or never & 8.7 & 7.1 & \\
\hline
\end{tabular}

${ }^{*} P<0.05 ;{ }^{* *} P<0.001$.

† Adjusted for age, gender, education level and body mass index group using logistic regression. 
meals, and had less structured meals with more snacking on energy-dense snack foods such as crisps.

Nearly two-thirds of French compared with just over half of English respondents reported eating together as a household on a daily basis. Our findings support those of an earlier study ${ }^{15}$ which reported that, in France and Southern Europe, 'getting together' was the first motivation for eating, and this region of France appears to share this value of the traditional Mediterranean lifestyle. This ties in with results from another component of this study, which found that the pleasurable and social aspects of eating were of greatest importance to the French ${ }^{22}$. However, the composition of 'households' has changed over recent years in the $\mathrm{UK}^{29}$. Although house sharing is common in the UK, this is less so in France, where oneperson households are increasing ${ }^{30}$.

More female than male respondents in both countries reported being responsible for preparing meals, but particularly more English females than French. This was also the case for deciding which foods are purchased and doing food shopping. This suggests a persistence of the gender differentiation within the domestic setting with regard to food provision ${ }^{10,31}$. Women in the UK are spending more time than previously doing supermarket shopping and travelling to food suppliers ${ }^{32}$. This may be due to their heavier reliance on convenience foods (foods that have been pre-prepared commercially and so require little preparation by the consumer). There is also recent evidence suggesting that children may exert significant control in the food provision decision-making process ${ }^{33}$, although the current study did not collect data on this.

A staggering two-thirds of French respondents cooked a meal from raw ingredients on a daily basis compared with less than a quarter of English respondents, which supports the findings from the attitudinal component of this study ${ }^{22}$ that reported that the French were more prepared to make time for cooking and attached more value to cooking from raw ingredients. This is perhaps to be expected, given the great pride that the French associate with their national cuisine $^{34}$ and perhaps accentuates the historical ongoing 'battle' between English and French cooking practices ${ }^{35}$. This is also supported by recent 'social trends' data in the UK, where it has been reported that time devoted to eating at meals and snacks at home has fallen in the last few decades $^{32}$.

The gender division of cooking meals from raw ingredients was more defined in France, with far more females than males responsible for this task. One explanation could be the fact that a higher proportion of the English sample (including females) was in paid employment, therefore relying more on convenience foods. These findings concur with those of an earlier study $^{19}$ reporting that the British population consumes more convenience food than any other European country. Younger adults used ready-prepared meals most often, particularly in England. This could be explained by the proposed transition in cooking skills described in the $\mathrm{UK}^{36}$, which clearly influences what people choose to prepare and eat ${ }^{37}$, and in France that younger people are moving away from traditional models of eating ${ }^{20}$. However, there is recent evidence examining domestic cooking skills which reports difficulties in discriminating between 'cooking from scratch' and 'cooking with preprepared foods ${ }^{38}$ as it depends on the particular foods being used and the skills needed to prepare them. The apparent cultural shift in shopping habits, cooking skills and food preparation would not be an issue if preprepared and convenience foods conformed to recommendations for healthy eating. Moves are already afoot to reduce the salt and sugar content of many such foods, but shifting of responsibility is paramount and consistent messages need to be relayed to all partners concerned, i.e. food industries, marketing organisations, policy-makers as well as consumers.

The French had the most regular meal pattern as they were most likely to consume all three meals daily, skipping breakfast and lunch less frequently than the English. In both countries, younger respondents were more likely to miss breakfast. In Britain the main meal is traditionally in the evening ${ }^{39}$. The fact that lunch was a more important meal for the French is characteristic of Mediterranean regions, although evidence of a swing towards the evening meal is emerging due to changing working patterns ${ }^{40}$. However, the 'de-structuration' of French eating habits, reported in an earlier study ${ }^{41}$, was not so evident and certainly does not yet equal that seen in the English study population. It appears that although English eating habits are less structured than traditionally, a new structure is emerging, based on convenience foods and households eating and preparing foods individually. This demise of long-established rules has led to a state that has been referred to as 'gastro-anomy' 42 .

Britons have been described as Europe's largest consumers of snacks ${ }^{43}$ and our results do not contradict this. Crisps in particular are one of the UK's most popular snacks, especially with young people, as they represent $60 \%$ of all savoury snacks sold in the $\mathrm{UK}^{44}$ and half of English respondents in our study ate crisps at least weekly. Research has highlighted confusion surrounding the precise definition of a 'snack': in Britain ${ }^{45}$, 'having a snack' was reported as being perceived differently from 'snacking' or eating 'snack food'. This ambiguity may be further accentuated by cross-cultural differences. We report on snack foods as being those eaten outside normal mealtimes. The different snacking patterns in Southern France have been reported previously ${ }^{46}$, finding that snacking amongst nurses in Toulouse was rare, but when they did snack they chose bread, cheese, yoghurts and fresh fruit rather than cakes, sweet biscuits or confectionery. However, recent food surveys in France show that there has been an increase in the intake of 'snack' and 'fastfood' products, for both pleasure and convenience ${ }^{47}$. 
These findings are alarming as energy-dense foods are known to be associated with promotion of weight gain and obesity ${ }^{48}$. The way such foods are marketed and advertised is an area in need of special attention.

Although attempts were made to optimise response rates $^{24}$, these were lower than expected and samples were not as representative of the populations as desired: our study over-sampled for males/older people and undersampled for females/young people in Nottingham ${ }^{28}$, but was representative of population gender and age distribution in Montpellier ${ }^{27}$. However, analyses adjusted for sociodemographic differences between samples so that findings are due to French or English residency.

In conclusion, some of the findings from this study confirmed popular stereotypes of French and English food cultures. The convivial aspects of eating, as well as more traditional practices, such as cooking meals from basic ingredients, were found to be more prominent within the French population. The heavy reliance on convenience food in the form of ready-prepared meals, take-away and snack food items in the English population also confirmed current stereotypes. These cultural differences may partly explain the higher prevalence of adult obesity in England than France. Public health nutrition professionals are in the position to develop interventions and policies that take into account the different cultural contexts of the current obesity epidemic.

\section{Acknowledgements}

The authors are grateful to Professor Andrew Salter for his academic support and to both Sabrina Eymard-Duvernay and Vicki Owen for their invaluable statistical guidance.

\section{References}

1 Mennell S. All Manners of Food: Eating and Taste in England and France from the Middle Ages to the Present. Chicago, IL: University of Illinois Press, 1996.

2 Rogers B. Beef and Liberty: Roast Beef, John Bull and the English Nation. London: Chatto \& Windus, 2004.

3 Lewin K. Forces behind food habits and methods of change. The problem of changing food habits. Bulletin of the National Research Council 1943; 108: 35-65.

4 Yudkin J. Man's choice of food. Lancet 1956; 270: 645-9.

5 Meiselman HL. Dimensions of the Meal: The Science, Culture, Business and Art of Eating. Gaithersburg, MD: Aspen Publishers, 2000.

6 Frewer L, Risvik E, Schifferstein H. Food, People and Society: A European Perspective on Consumers' Food Choices. New York: Springer, 2001

7 Fischler C. Food, self and identity. Social Science Information 1998; 25: 945-65.

8 Mela DJ. Food choice and intake: the human factor. Proceedings of the Nutrition Society 1999; 58: 513-21.

9 Fieldhouse P. Food and Nutrition, Customs and Culture. Cheltenham: Stanley Thornes, 1996

10 Mennell S, Murcott A, van Otterloo AH. Sociology of Food: Eating, Diet and Culture. London: Sage Publications, 1992.

11 Marshall DW. Food Choice and the Consumer. London: Blackie Academic \& Professional, 1995.
12 Tansey G, Worsely T. The Food System. London: Earthscan, 1995.

13 Gerber M, Padilla M. Consommation Mediterranean: Une Action Préventive au Cancer. Final Report, CCE DGV Programme against Cancer, 1998.

14 Rozin P. Towards a Psychology of Food Choice. Danone Chair Monograph. Brussels: Institut Danone, 1998.

15 Volatier JL. Le repas traditionnel se porte encore bien. CREDOC consommation et modes de vie 1999; (132).

16 Wright LT, Nancarrow C, Kwok PMH. Food taste preferences and cultural influences on consumption. British Food Journal 2001; 100: 348-57.

17 Burnett J. Plenty and Want: A Social History of Food in England from 1815 to the Present Day. London: Routledge, 1989.

18 Warde A, Martens L. Eating Out: Social Differentiation, Consumption and Pleasure. Cambridge: University Press, 2000.

19 Schlosser E. Fast Food Nation: What the All-American Meal is Doing to the World. London: Penguin Press, 2001.

20 Scali J, Richard A, Gerber M. Diet profiles in a population sample from Mediterranean southern France. Public Health Nutrition 2000; 4: 173-82.

21 Holdsworth M, Gerber M, Haslam C, Scali J, Beardsworth A, Avallone $\mathrm{MH}$, et al. A comparison of dietary behaviour in Central England and a French Mediterranean region. European Journal of Clinical Nutrition 2000; 54: 1-10.

22 Pettinger C, Holdsworth M, Gerber M. Psycho-social influences on food choice in Southern France and Central England. Appetite 2004; 42: 307-16.

23 Oppenheim AN. Questionnaire Design, Interviewing and Attitudes Measurement. London: Pinter, 1992.

24 Edwards P, Roberts I, Clarke M, DiGuiseppi C, Pratap S, Wentz R, et al. Increasing response to postal questionnaires: systematic review. British Medical Journal 2002; 324: 1168-9.

25 Meeuwisse WH, Hagel BE, Fick GH. The impact of single versus dual data entry on accuracy of relational database information. Journal of Informatics in Primary Care 1999: (June): 2-8.

26 SPSS Inc. Statistical Package for the Social Sciences, Version 11.0 for Windows. Chicago, IL: SPSS Inc., 2001.

27 Institut National Statistique et des Etudes Economiques (INSEE). Recensement de la population de 1999. Les resultats. Paris: INSEE, 2001.

28 Office of Population Censuses and Surveys. Census 2001. National Report for England and Wales. London: HMSO, 2003.

29 Beardsworth A, Keil T. Sociology on the Menu: An Invitation to the Study of Food and Society. London: Routledge, 1997.

30 Institut National Statistique et des Etudes Economiques (INSEE). Les structures familiales en Languedoc-Roussillon. Résultats complémentaires de la Recensement de la population de 1999. Paris: INSEE, 2001.

31 Rozin P, Fischler C, Imada S, Sarubin A, Wrzesniewski A. Attitudes to food and the role of food in life in the USA, Japan, Flemish Belgium and France: possible implications for the diet-health debate. Appetite 1999; 33: 163-80.

32 Gershuny J, Fisher K. Leisure. In: Halsey AH, Webb J, eds. Twentieth-Century British Social Trends. London: Macmillan Press, 2000; 620-49.

33 Dixon J, Banwell C. Heading the table: parenting and the junior consumer. British Food Journal 2004; 106: 181-93.

34 Monneuse MO, Bellisle F, Koppert G. Eating habits, food and health related attitudes and beliefs reported by French students. European Journal of Clinical Nutrition 1997; 51(Suppl. 2): S46-53. 
35 Tannahill R. Food in History, revised ed. Harmondsworth: Penguin, 1988.

36 Caraher M, Lang T. Can't cook, won't cook: a review of cooking skills and their relevance to health promotion. International Journal of Health Promotion and Education 1999; 37: 89-100.

37 Caraher M, Dixon P, Lang T, Carr-Hill R. The state of cooking in England: the relationship of cooking skills to food choice. British Food Journal 1999; 101: 590-609.

38 Short F. Domestic cooking skills. Journal of the Home Economics Institute of Australia 2003; 10: 13-22.

39 Marshall DW. British meals and food choice. In: Meiselman HL, ed. Dimensions of the Meal: The Science, Culture, Business and Art of Eating. Gaithersburg, MD: Aspen Publishers, 2000; 202-20.

40 Padilla M, Aubaille-Sallenave F, Oberti B. Eating behaviour and culinary practices. In: Besançon $\mathrm{P}$, Debosque S, Delpench F, Descomps B, Gerber M, Léger C-L, et al., eds. Mediterranean Diet and Health: Current News and Prospects. London: John Libbey, 2001; $113-27$.
41 Poulain JP. The contemporary diet in France: 'de-structuration' or from commensalism to 'vagabond feeding'. Appetite 2002; 39: 43-55.

42 Fischler C. Food habits, social change and the nature/culture dilemma. Social Science Information 1980; 19: 937-53.

43 Mintel International Group Ltd. Snacks - Pan-European Overview. European Consumer Goods Intelligence Series. London: Mintel International Group Ltd, 2003.

44 European Snacks Association (ESA). The History of the Snack. Consumer information. London: ESA, 2000.

45 Chamontin A, Pretzer G, Booth DA. Ambiguity of 'snack' in British usage. Appetite 2003; 41: 21-9.

46 Pettinger C. Snacking behaviour in Southern France and the UK. In: Health Inequalities in Europe. Congress Book of Abstracts. Paris: Société Française de Santé Publique \& European Public Health Association, 2000; 378.

47 Volatier JL. Principaux résultats, Enquête INCA, 1999. Présentation de l'enquête INCA. Paris: REDOC \& AFSSA, Agence Française de securité Sanitaire des Aliments, 2000.

48 Prentice AM, Jebb SA. Fast foods, energy density and obesity: a possible mechanistic link. Obesity Reviews 2003; 4: 187-94. 